\title{
Innovative Plant for the Production of Microalgaes
}

\author{
Farné Stefano
}

Department of Industrial, Electrical, Computer and Biomedical Engineering, University of Pavia, Italy.

DOI: $10.38177 / a j a s t .2020 .4318$

Crossref

\section{ABSTRACT}

It is strongly felt the need to replace fossil fuels with other renewable and more compatible with the environment. The spinneret of algal crops is producing different solutions ("open ponds", tubular, bioreactors in greenhouses, etc.). The aim is to obtain concentrations of dry substance such as to justify the high costs of extraction. Another limitation suffered by the actual plants, derives from the choice to move the algal mass (process characterized by a high energy consumption), with actions necessary to keep it in suspension as well as to move it, to exchange its positioning in order to bring it to be conditioned by the light (exhausting its effectiveness after the first 0.2-0.3 $\mathrm{m}$ of algal mass depth, or even less if thicker and when it would need more light for its exponential growth). In particular, it is not possible to bring a specific radiation spectrum, in a pervasive and deep way, with a drastic cost reduction for the mechanical movement of the culture medium. A limitation derives also from the possibility of biological and chemical contamination from the environment, because the algal mass is in a large contact with the environment itself (e.g. the "open ponds" situations) and it is heavily exposed to the prevalent thermal cycles (often not suitable to the processes of growth) inside it. Some problems are often encountered even in the phase of collection and selection of the algal mass to be forwarded to the following processes, that proceeds through the massive processing of large volumes (by filtration and concentration) that, due to previous limitations (contamination and uncertain conditions of growth), remain at low concentrations. The purpose of this article is to present the PBRC (Photo Bio Reactor Continuous) plant, subject of an Italian patent [Lavanga and Farné, 2014], for the cultivation of microalgae, from which to extract an oleic fraction, which can be destined for production of biofuels, and a protein fraction, which can be destined for use in the chemical, agri-food, pharmaceutical and cosmetic sectors.

\section{Introduction}

Microalgae (fig. 1) are photoautotrophic, prokaryotic or eukaryotic single-celled organisms, which have numerous advantages, including fast growth [Mata et al., 2010], if light and simple nutrients are available and the ability to synthesize and accumulate lipids, proteins and carbohydrates.

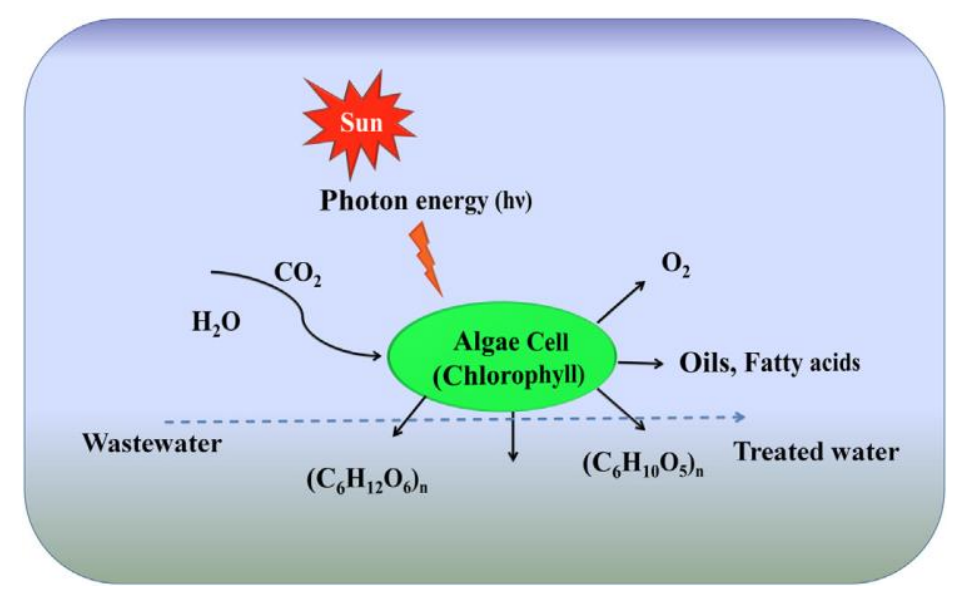

Fig.1 Microalgae use light energy (e.g. the sun) for the production of chemical energy through photosynthesis during the natural growth cycle

Microalgae can be grown in open systems (Open Ponds), such as lakes, ponds, or closed in culture systems called photobioreactors (reactors in which phototrophic organisms - microbial, algal or plant cells - are grown or used to carry out a photobiological reaction) [Mata et al., 2010], as shown in fig.2. The choice of the culture system is based on several factors: the culture medium, the amount of water, nutrients, temperature, energy consumption and the final product that is intended to be obtained. 


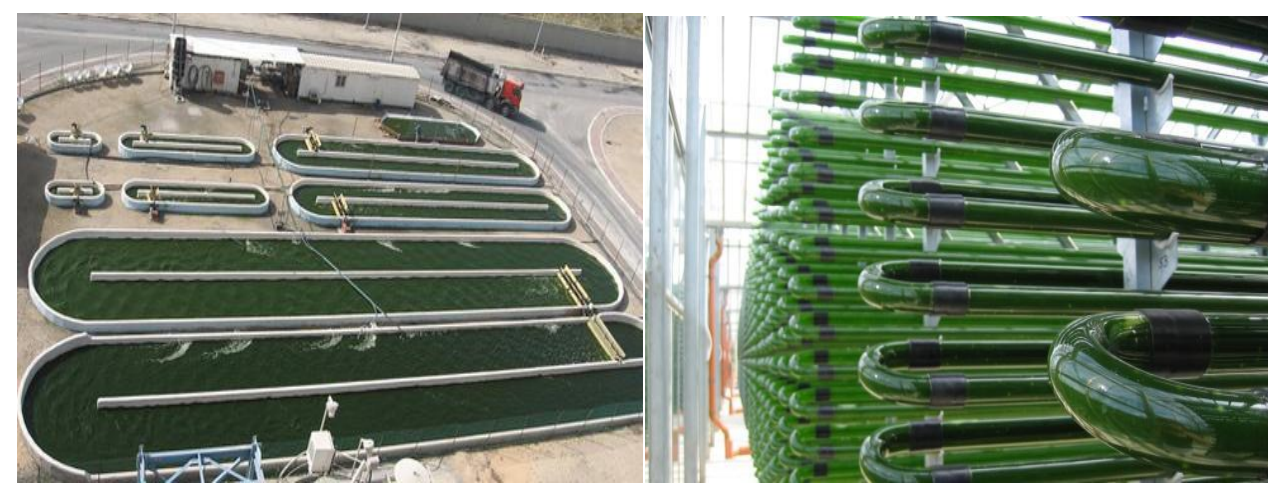

(a)

(b)

Fig.2 Examples of cultivation system: (a) open system (raceway ponds) and (b) closed system (tubular photobioreactor)

\subsection{Open Ponds}

Currently the cultivation of microalgae at industrial level takes place in production systems based on open ponds. The main reason is the cost-effectiveness of the system, due to the simplicity of management and linked to both low construction and operating costs.

The most widely used at industrial level are of two types: the "inclined" systems, where mixing is given by gravity and pumps, and the "circuit" tanks (raceway pond) where the mass completes a closed circuit moved by rotating blades. The second type, schematically represented in fig. 3 , is certainly the most common.

The simplest model is represented by a tank of variable thickness (from $0.15 \mathrm{~m}$ to $0.30 \mathrm{~m}$ ), covered by a plastic sheet that does not allow losses of the crop through the ground. The blades are always on the move to prevent sedimentation but the crop only grows in the daytime where sunlight hits the surface of the tank.

Open pond technologies present many problematic aspects that limit their productivity. For example, the thickness cannot be less than $0.15 \mathrm{~m}$ (which would allow the volumes involved to be lowered) because otherwise there would be no more good mixing and it cannot exceed $30 \mathrm{~cm}$ otherwise there would be problems with the penetration of the sun's rays with a relative decrease in the efficiency [Richmond, 2004].

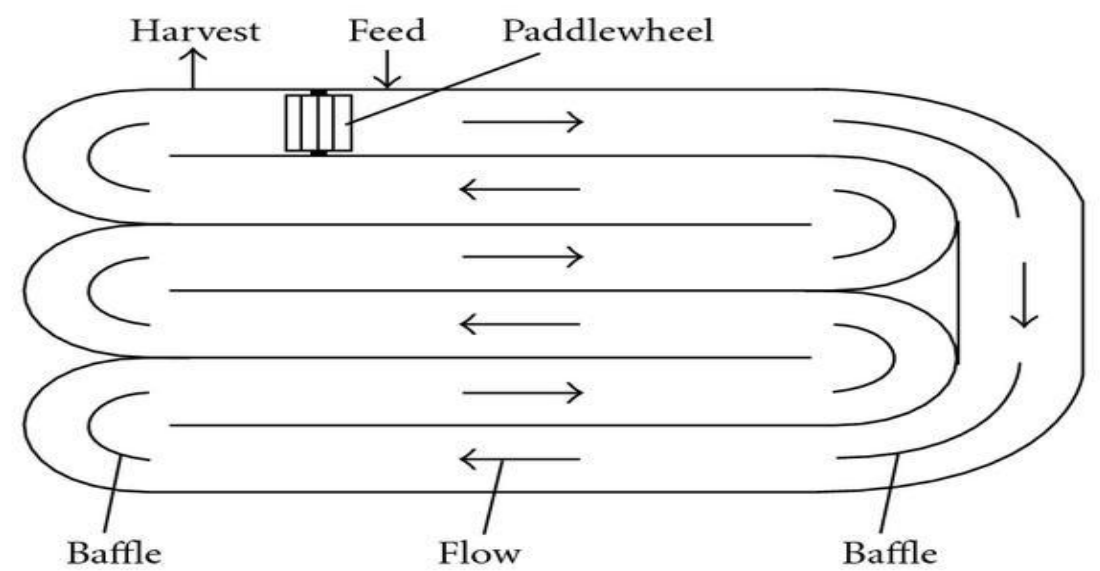

Fig.3 Plan view of a raceway pond (Chisti, 2007) 
The algal concentration is very low and this facilitates contamination as well as increasing the costs of separating biomass from the aqueous mass. In addition, area productivity has a limit of $12-13 \mathrm{~g} / \mathrm{m}^{2}$ per day [Norsker et al., 2011] unless substantial changes are made to the technology, making it lose its main characteristic, that is, economy and ease of operation. Outdoor systems are sensitive to climatic variations and they are very affected by the phenomenon of evaporation, which makes this system inefficient in the use of water resources. Another problem is the great need for cultivation areas and therefore for volumes to be treated which, at the same productivity level, are higher than in a closed system, due to the lower effectiveness in the exploitation of photosynthesis. The $\mathrm{CO}_{2}$ distribution is also less efficient than a in a photobioreactor.

\subsection{Photobioreactors}

Photobioreactors allow growing crops avoiding contamination and are of different types, tubular reactors, bubble reactors, horizontal, vertical and flat-plate. The tubular reactors consist of a series of transparent, glass or plastic tubes, inside which the culture is made to flow. The pipes must be exposed to the light source, which can be artificial or solar. The diameter of the pipes is limited because the algae must not be allowed to remain in the shade otherwise they would not receive enough energy to grow. For this reason, pipes with diameters greater than $0.10 \mathrm{~m}$ are rarely built [Chisti, 2007]. The culture is recirculated from the inside of the tubes to a degassing column where the fresh medium is fed. Fig. 4 shows a typical scheme of a tubular photobioreactor. The movement of the aqueous mass can take place by pumping or by blowing air. This method involves less mechanical stress applied to the cells and therefore less chance of damaging them. It allows a better exchange between the $\mathrm{CO}_{2}$-rich gas phase and the liquid phase [Xu et al., 2009]. The arrangement of the pipes must be such as to maximize the light irradiation, therefore the pipes are arranged in a north-south direction and often the surface that support the pipes is made white (by a coating for example) to reflect the light and to increase the exposure of the crop. Many tubular reactors are built in a helical shape, around a cylindrical structure.

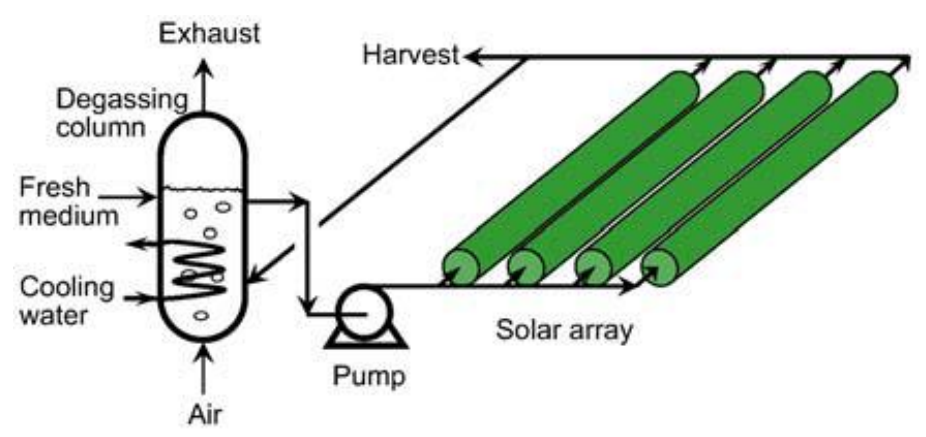

Fig.4 Typical scheme of a tubular photobioreactor with relative degassing column

\subsection{Kinematic model}

\subsubsection{Growth kinetics of microalgae}

The present study was conducted assuming the cultivation of an algal species called Chlorella. The most important parameter is the one that describes the average light intensity inside a reactor, from which the average irradiation available for a single cell inside the culture is calculated [Molina Grima et al. 1995, 1999]. Since the penetration of 


\section{AJAST}

Asian Journal of Applied Science and Technology Volume 4, Issue 3, Pages 145-166, July-September 2020

light is highly limited due to the high cell density, only the average irradiance (rather than the irradiance falling on the illuminated culture area) provides a meaningful value of the crop response to the light irradiation.

\subsubsection{Growth rate of microalgae}

The maximum growth rate is the one that is reached in the exponential phase (fig. 4), where there is no limitation due to the substrate.

The specific growth rate $\mu\left[\mathrm{h}^{-1}\right]$ is defined as the increase in cell mass for unit of time for unit of cell mass [Sandnes et al., 2005]

$\frac{d N}{d t}=\mu \cdot N$

Where, $\mathrm{N}$ is the number of cells, $\mathrm{t}$ is the time and $\mu$ is the growth rate.

By integrating the equation (1) between the initial conditions (i) and the final conditions (f), it is obtained:

$\ln \frac{N_{f}}{N_{i}}=\mu *\left(\mathrm{t}_{\mathrm{f}}-\mathrm{t}_{\mathrm{i}}\right)$

In an equivalent shape:

$\mu=\frac{\ln \frac{N_{f}}{N_{i}}}{t_{f}-t_{i}} \quad\left[h^{-1}\right]$

Fig.5 shows the semi-logarithmic graph of the cellular concentration of algae and the linear interpolation of the points representative the exponential phase.

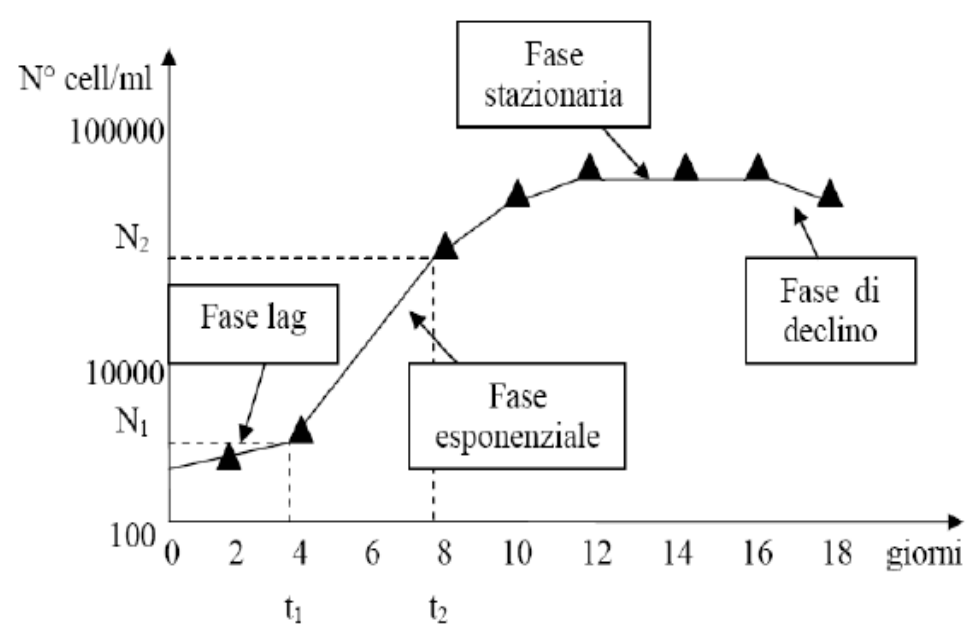

Fig.5 Schematic representation of the growth curve of microalgae

For the calculation of the growth rate, the points relating to the exponential phase are taken into consideration, and from the equation (2):

$\ln \frac{N}{N_{0}}=\mu *\left(\mathrm{t}-\mathrm{t}_{0}\right)$

It is defined that the growth rate is the slope of the straight line of linear interpolation of the chosen points. 


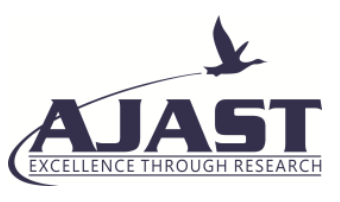

Asian Journal of Applied Science and Technology Volume 4, Issue 3, Pages 145-166, July-September 2020

The growth of microalgae in a reactor in which the nutrients are present in sufficient quantities and the climatic conditions are adequate presents a characteristic trend represented in fig. 4.

The curve of the growth of microalgae highlights four phases:

1. Latency phase (lag): adaptation of microalgae to the culture medium (synthesis of proteins, ATP, enzymes); the growth rate is zero.

2. Exponential phase: microorganisms grow at maximum speed; the number of microalgae doubles at regular time intervals. The growth rate is constant and depends on the availability of nutrients, temperature and light.

3. Stationary phase: the scarcity of nutrients and the accumulation of toxic metabolites slow down the growth to zero; the growth rate is zero and the number of organisms constant.

4. Decline phase: the number of viable cells decreases as both the division and the metabolic phase are suspended. It generally occurs following an excessive algal concentration, the depletion of nutrients in the culture medium and the establishment of adverse growth conditions (unsuitable temperatures, the presence of toxic substances, inadequate lighting).

The growth of microalgae depends on several variables:

- abiotic factors: light (intensity and wavelength), temperature, concentration of nutrients, oxygen, carbon dioxide, $\mathrm{pH}$, salinity and toxic substances;

- biotic factors: pathogens (bacteria, fungi, viruses) and other competing algae;

- operating variables: mixing, ratio between volumetric flow rate and reactor volume (dilution rate), depth of the reactor with respect to the surface on which the light engrave, harvest frequency.

\subsection{Molina Grima kinematic model}

It starts from the definition of medium intensity $I_{a v}$ as the volumetric average of the punctual intensities found within a photobioreactor by virtue of the distribution of light [Richmond, 2004]

$I_{a v}=\frac{1}{V} \int_{V} I d V$

The individual microalgae continuously move between areas of different light intensity and each cell undergoes an instantaneous change in exposure levels.

In a perfectly stirred reactor, the growth rate $\mu\left[\mathrm{h}^{-1}\right]$ can be expressed as a function of $\mathrm{I}_{\mathrm{av}}$ [Molina Grima et al., 1994]:

$\mu=\mu_{\max } \frac{I_{a v}^{q}}{I_{k}^{q}+I_{a v}^{q}}$

Where, $\mu_{\max }$ is the maximum growth rate $\left[\mathrm{h}^{-1}\right]$ and $\mathrm{I}_{\mathrm{k}}\left[\mu \mathrm{Em}^{-2} \mathrm{~s}^{-1}\right]$ is a specific irradiance constant that represents the $I_{a v}$ able to give a growth rate equal to half of the maximum one.

The model has a significant advantage over the numerous other models of this type published in the literature: that of taking into account the fundamental phenomena of photoinhibition and photolimitation. In fact, it is assumed 


\section{AJAST}

Asian Journal of Applied Science and Technology

Volume 4, Issue 3, Pages 145-166, July-September 2020

that photoinhibition takes place only at very high luminous intensities, which are found in limited volumes of the reactor and close to the irradiated surface.

To take into account the phenomenon, the parameter q of the equation ( 5 ) is expressed as a function of the greater light intensity that can be manifested in the ballast, i.e. that at the surface $\mathrm{I}_{z=0}$; in the remaining areas of the reactor, even in those subject to photolimitation, it is assumed that the regeneration of the damaged cells takes place [Molina Grima et al., 1999].

$\mu=\mu_{\max } \frac{I_{a v}^{\left(b+\frac{c}{I_{Z=0}}\right)}}{\left[I_{k}\left(1+\left(\frac{I_{Z=0}}{K_{i}}\right)^{a}\right)\right]^{\left(b+\frac{c}{I_{Z=0}}\right)}+I_{a v}^{\left(b+\frac{c}{I_{Z=0}}\right)}}$

The value of the light absorption coefficient must also be estimated, starting from the value of the light intensity; since the radiation intensity decreases exponentially throughout the optical path and the radiation intensity on the edge of the illuminated side of the reactor is denoted with $\mathrm{I}_{0}$, then the intensity at a distance $\mathrm{x}$ from the illuminated side of the flat reactor is given by [Richmond, 2004]:

$I(x)=I_{0} e^{-k_{\lambda} \cdot x}($ law of Lambert-Beer $)$

Where, $k_{\lambda}$ is the attenuation coefficient (which is a typical constant of the medium crossed and depends on the wavelength $\lambda$ ) and $x$ is the thickness of the crossed solutions (if $\mathrm{x}$ is in $\mathrm{cm}$, then $k_{\lambda}$ will be in $\mathrm{cm}^{-1}$ ). The average radiation is given by an average value of $\mathrm{I}(\mathrm{x})$ over the entire optical path $(0 \leq \mathrm{x} \leq \mathrm{L})$ :

$I_{a v}=\frac{1}{L} \int_{0}^{L} I(x) d x=\frac{I_{0}}{L} \int_{0}^{L} e^{-k_{\lambda} \cdot x} d x=I_{0} \frac{1-e^{-k_{\lambda} L}}{k_{\lambda} L}$

To get an idea of how the average radiation intensity varies with the density of the crop, linear approximation is used. So the expression for medium intensity becomes:

$I_{a v}=I_{0} \frac{1-e^{-\alpha \rho L}}{\alpha \rho L}$

\section{Materials and Methods}

\subsection{PBRC (Photobioreactor Continuous) description}

The photobioreactor, called PBRC, consists of a tank of a thickness suitable for the pressure exerted inside. The volume of the tank, thermally insulated towards the outside, is divided transversely into two macro-sectors of different length. In the volume with greater length the cultivation of microalgae will take place, while in the volume of shorter length the gravimetric separation of the biomass will take place, through a sonotrode which has the function to emit ultrasound that break the cellular structure of microalgae.

Only in the culture sector, there is a heating from below through radiant panels. The culture sector consists of several panels, suitably arranged to create a sinuous path. These panels are made of plastic sheets with side-emitting optical fiber cables inside [Lavanga, Farné SDNA, 2014], with the aim of allowing a homogeneous light diffusion.

Fig. 6 represents the PBRC tank for the growth of microalgae. 


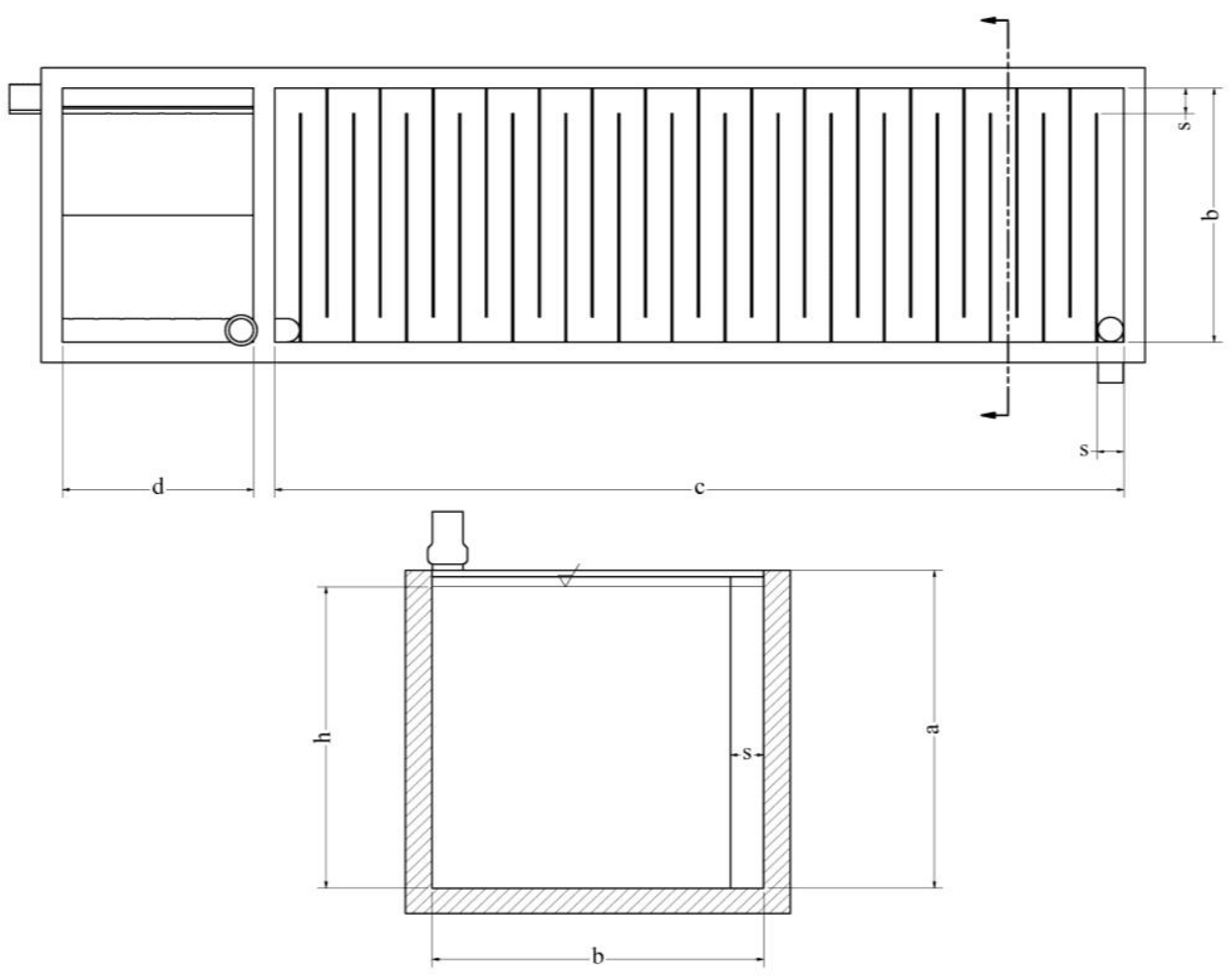

Fig.6 Elevation and section of the PBRC tank

A. The overall length of the sinuous path imposed by the baffles will allow, through a defined speed, to give, in the last stretch, the optimal concentration and therefore ready for extraction

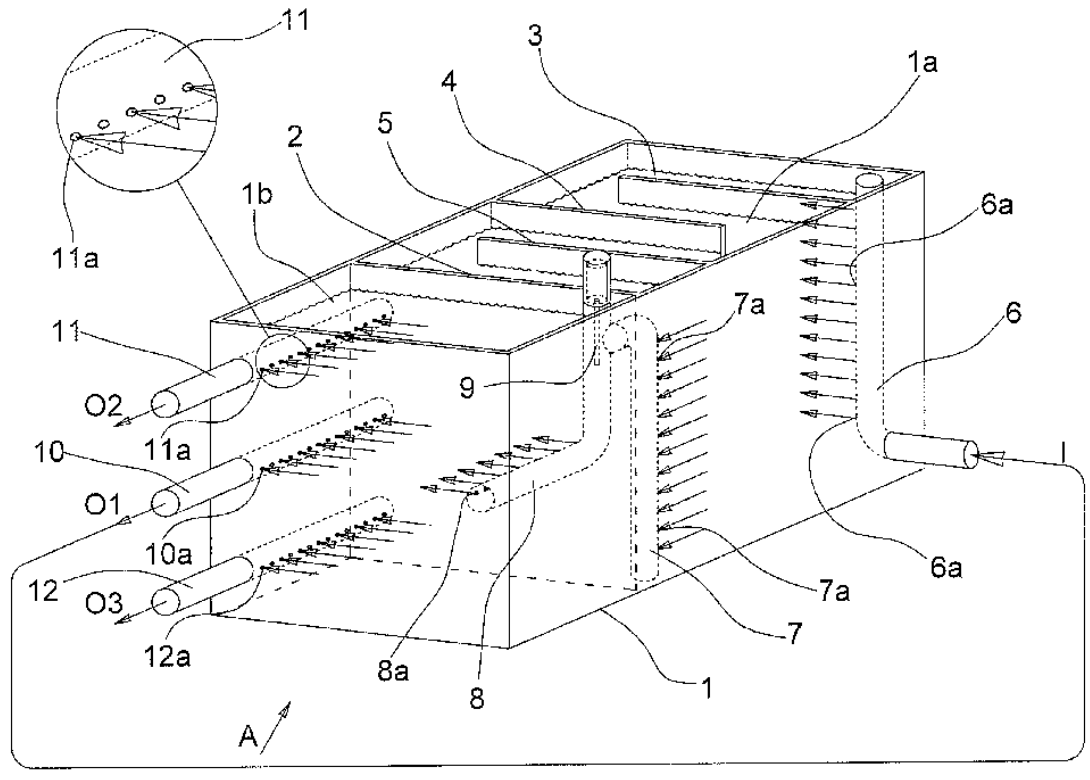

Fig. 1

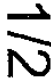

Fig.7/1 Device according to the invention 


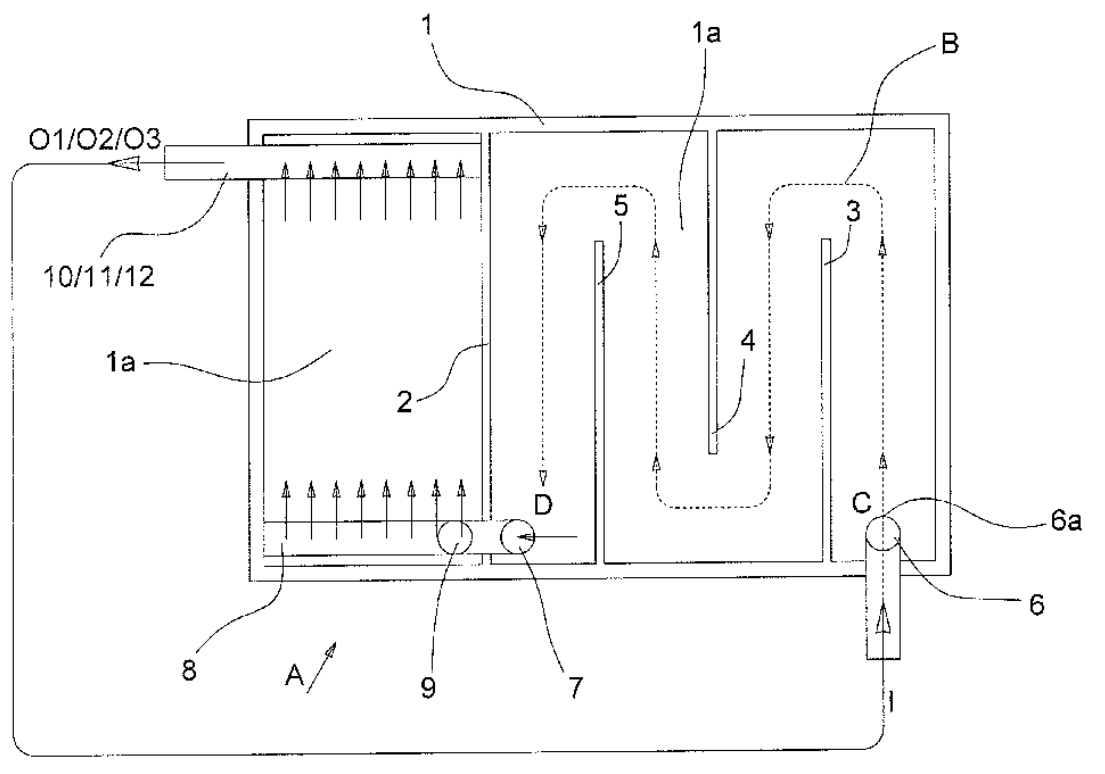

Fig. 2

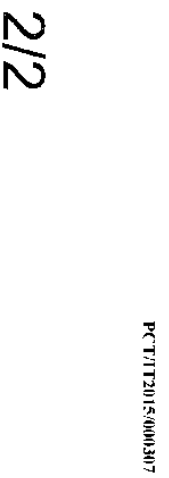

Fig.7/2 Plan view of the device according to the invention, illustrating the path of the fluid mixture in treatment

With reference to figures 7/1 and 7/2, with (A) it is indicated a device according to the invention, fitted to cultivate microalgae and to separate the oleic and protein components. Said device (A) comprises a basin (1), predisposed for the phases of culture and extraction in the condition of communicating vessels, inside which it is positioned a first baffle (2) which divides the basin (1) in a first part (1a) and in a second part (1b).

Inside the first part (1a) of the basin (1) it is present a plurality of alternate baffles $(3,4,5)$ fitted to delimit a sinuous path (B) from a point (C) to a point (D). The alternate baffles $(3,4,5)$ being homogeneous diffuser panels of a radiation spectrum suitable to the cultivation phase. In order to be able to properly irradiate the mixture, the thickness of said flow is preferably not higher than $20 \div 30 \mathrm{~cm}$. Furthermore, along the path (B) are present means to provide the fluid mixture with NPK salts (nitrogen, phosphorus and potassium) and C02. The tank (1) is preferably insulated outside and heated from below, for example by radiant systems to the floor (not shown) for supporting a slight excitation through convective motions so as to create the ideal conditions for the culture. The flow of the mixture, watery based, containing the inoculum, including a small amount of microalgae to be cultured, indicated with the arrow (I), is introduced in the first part (1a) of the basin (1) through a first inlet pipe (6), vertically positioned in coincidence of the point $(\mathrm{C})$ of the beginning of the path $(\mathrm{B})$.

The mixture comes out the tube (6) through a plurality of holes (6a) aligned along a generatrix of said first inlet tube (6). The watery mixture, after the path (B), reaches the point (D) and runs into a second tube (7), through a plurality of holes (7a) aligned along a generatrix of the second tube (7). In order to obtain a more regular flow, the inlet of the watery mixture takes place in the bottom part of the first inlet tube (6), while the output of the mixture takes place at the top of the second tube (7), according to a scheme of reverse return. From the second pipe (7), the watery mixture passes into a third tube (8) and, from this, passes in the second part (1b) of the tub (1). The passage from the third 
tube (8) to the second part (1b) of the tub (1) takes place through a plurality of holes (8a) aligned along a generatrix of the third tube (8). The part of the third tube (8) in which it is present the plurality of holes (8a) is arranged horizontally and is positioned at about half the height of the basin (1). In the top vertical position of the third tube (8), preferably in coincidence of the zone in which the second pipe (7) enters in the third tube (8),it is positioned a sonotrode probe (9), the function of which will be described hereinafter. The mixture leaving the third tube (8) passes through the second part (1b) of the basin (1) and reaches, on the opposite side, three outlet tubes, intermediate (10), upper (11) and lower (12) parallelly arranged to the third tube (8). The three outlet tubes (10), (11) and (12) are provided with holes (10a), (11a) and (12a) respectively, aligned along a generatrix. In the enlarged detail of the upper tube (11) the holes (11a) are shown; the enlarged detail is representative of the holes made on all tubes inside the basin (1). In the path from the third tube (8) to the three outlet tubes (11), (12) and (13), the mixture is subjected to the separation of the fractions oleic, that goes upwards, and protein, that goes downwards, leaving at half height a fraction composed almost exclusively of water. Proceeding towards the outlet tubes, the watery fraction is directed mainly towards the central tube (10), from which it comes out, as indicated by the arrow (O1). Similarly the oleic fraction, lighter, goes upwards and comes out from the upper tube (11), forming a flow (O2), while the protein fraction, heavier, goes downwards and comes out from the lower tube (12), forming a flow (03). The intermediate flow (01) containing the inoculum, enriched by water, is recycled through said first inlet tube (6) for a new treatment. The operation of the device (A), that is also the method of treatment according to the invention, is the following:

- the watery mixture containing the inoculum, substantially constituted by a small amount of microalgae, is introduced in the first part (1a) of the basin (1) through the first inlet tube (6);

- the mixture follows the path (B), from the inlet point (C) to the outlet point (D) along which it is irradiated by a radiation spectrum suitable to the development and the growth of the microalgae;

- along the path (B) they are added the NPK salts (containing nitrogen, phosphorus and potassium) in appropriate titre, and $\mathrm{CO} 2$, these additions, together with the diffusion of an appropriate radiation spectrum, causes an intense growth of algae, said growth being able to reach a hourly rate of growth between $10 \%$ and $20 \%$;

- arrived in the fourth tube (8), the mixture is flooded by the ultrasounds emitted by the sonotrode probe (9) that destroys the algae splitting them in oleic and protein components, said division being suitably measured out through the adjustment of the power of the sonotrode, to preserve a small amount of algae;

- the resulting mixture, composed i.e. by a oleic fraction, a protein fraction and a small amount of not damaged algae, runs into the second part (1b) of the basin (1), where it undergoes a gravimetric separation;

- the oleic fraction, lighter, collects in the upper outlet tube (11) and form the output flow (02), while the protein fraction, heavier, collects in the lower outlet tube (12) and form the output flow (03); the neutral fraction, largely composed of water containing a small amount of not damaged algae, is recycled to the inlet tube (6) for a new cycle of culture. The process (depending on the unicellular strain and of its chemical-biological structure) can be supported by flocculating or chemical agents to facilitate the separation and its collection (functional as well as to 
Asian Journal of Applied Science and Technology Volume 4, Issue 3, Pages 145-166, July-September 2020

any subsequent treatments). The oleic (high) and the protein (low) components are extracted according to rates of flow correlated to the concentration of the relevant "solute" (detected by suitable densitometers), and the volumes of water must be properly replenished.

\section{Results and Discussion}

\subsection{Growth rate calculation}

Starting from an initial concentration of Chlorella microalgae of 1.34 [g / 1$]$ (starting inoculum $\rho_{\mathrm{i}}$ )

a final biomass density of $21.44[\mathrm{~g} / \mathrm{l}]$ is obtained.

Taking into consideration the microalgal species Chlorella, at a temperature of $35-37\left[{ }^{\circ} \mathrm{C}\right]$ and at a pH between 6 and 7.5, having a doubling of density every 6 hours, there is a maximum specific growth rate (3): $\mu=0.116\left[\mathrm{~h}^{-1}\right]$.

The doubling of the density every 6 hours is considered in order to always maintain a constant and contained growth rate in the maximum of the microalga taken into consideration (from the literature the limit value for Chlorella is $\left.0.13\left[\mathrm{~h}^{-1}\right]\right)$.

Table 1: Density of algal biomass

\begin{tabular}{|c|c|c|c|c|c|}
\hline Data & u.m. & value & value & u.m. & note \\
\hline $\begin{array}{c}\text { density of the chlorella } \\
\text { inoculum }\end{array}$ & $\mathrm{pi}\left(\mathrm{kg} / \mathrm{m}^{3}\right)$ & 1,340 & & & \\
\hline doubling density & $\mathrm{p}\left(\mathrm{kg} / \mathrm{m}^{3}\right)$ & 2,68 & & & \\
\hline $\begin{array}{c}\text { density of the final } \\
\text { biomass }\end{array}$ & $\mathrm{pf}\left(\mathrm{kg} / \mathrm{m}^{3}\right)$ & 21,440 & & & \\
\hline $\begin{array}{c}\text { growth rate } \\
\mathrm{h}^{-1}\end{array}$ & 0,116 & 0,693 & day & & \\
\hline initial time & $\mathrm{h}^{-1}$ & 0,000 & & & $\frac{\ln \frac{N_{f}}{N_{i}}}{t_{f}-t_{i}}$ \\
\hline final time & $\mathrm{h}^{-1}$ & 6,000 & & & Double of the density every \\
\hline
\end{tabular}

In table 2, the density values are reported, considering the doubling of the same every 6 hours.

Table 2: Density of algal biomass every $6 \mathrm{~h}$

\begin{tabular}{|c|c|c|}
\hline data & u.m. & value \\
\hline density $\mathrm{t}=0 \mathrm{~h}$ & $\mathrm{~kg} / \mathrm{m} 3$ & 1,340 \\
\hline density $\mathrm{t}=6 \mathrm{~h}$ & $\mathrm{~kg} / \mathrm{m} 3$ & 2,680 \\
\hline
\end{tabular}




\begin{tabular}{|c|c|c|}
\hline density $\mathrm{t}=12 \mathrm{~h}$ & $\mathrm{~kg} / \mathrm{m} 3$ & 5,360 \\
\hline density $\mathrm{t}=18 \mathrm{~h}$ & $\mathrm{~kg} / \mathrm{m} 3$ & 10,720 \\
\hline density $\mathrm{t}=24 \mathrm{~h}$ & $\mathrm{~kg} / \mathrm{m} 3$ & 21,440 \\
\hline
\end{tabular}

\subsection{Parameters that influence growth}

\subsubsection{Light}

Not all light is used for the process but only that corresponding to the portion of the electromagnetic spectrum with wavelengths between $400 \mathrm{~nm}$ and $700 \mathrm{~nm}$. The radiation belonging to this range is called "photosynthetically active" and is indicated by the term PAR. The greater the amount of light that microalgae receive, the greater their growth rate and therefore the ability to perform photosynthesis. This does not always apply, every species of microalgae has a maximum acceptable irradiance, beyond which photoinhibition phenomena are observed.

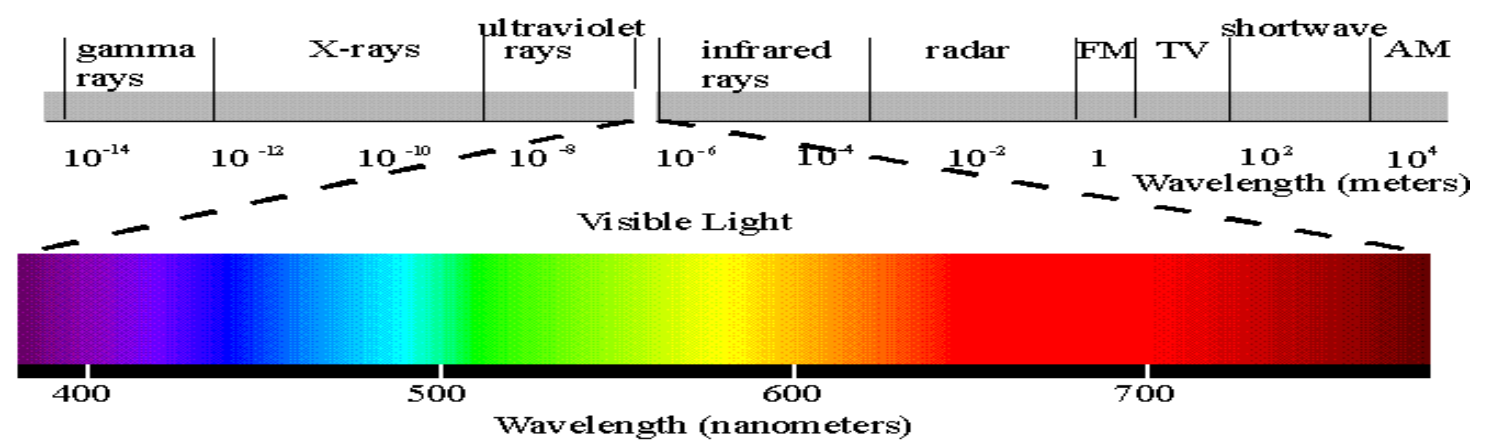

Fig.8 Electromagnetic spectrum in which the portion corresponding to visible light is highlighted

The PBRC tank is equipped with alternating dividing partitions that create a sinuous path inside the tank in which the microalgal solution moves; mounted on these partitions there are transparent panels incorporating an optical fiber which has the fundamental task of acting as a light source to carry out photosynthesis and to homogenise the radiation spectrum. These coplanar diffusers (SDNA) are arranged between them at a distance of between 0.25 and $0.30[\mathrm{~m}]$ and, since they illuminate from both directions, there is an attenuation of the light in a length of only 0.12 $-0.15[\mathrm{~m}]$ (significantly related to the powers exercised and to the crop density).

Each of these panels essentially consists of two sheets of transparent plastic material (polyethylene or the like), inside which a side glow (side emitting) optical fiber is contained under vacuum. The two sheets are welded together at the edges and in intermediate sections, and fixed inside the tank with appropriate guides.

The system described is the subject of an Italian patent [Lavanga and Farné, 2014], called SDNA (lights diffusor homogenous by side emission fiber). The light intensity, which enters from one end of the cable, will disperse laterally, then gradually decrease as it proceeds towards the exit end.

To ensure a homogeneous light diffusion over the entire surface, the cable is arranged, as can be seen in Figure 9, so that each infinitesimal length of the cable is flanked by the corresponding section with an opposite intensity, so that the sum is substantially the same. 


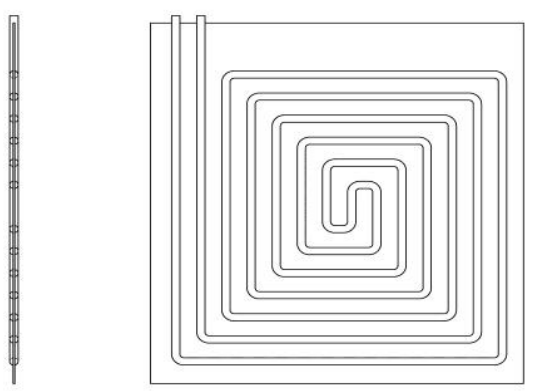

Fig.9 Fiber optic cable with lateral emission inserted between two polyethylene sheets arranged so as to guarantee homogeneous lighting

Each panel has its own illuminator system dedicated and piloted by PLC (Programmable Logic Controller), to dose frequency and intensity (power) in the progress of the series of panels, according to the programmed microalgal growth rates (the system can also use the CMTC system described in the following paragraph, by redirecting only the red / blue components of direct solar origin, the rest flows into thermal inputs, the whole is assisted by LEDs, by means of a PLC, for the phases of darkening the daytime weather and fully in the nighttime ones).

The advantages of using this technology are significant:

- the optical fiber gives off cold light as there is no heat transfer. This avoids the use of cooling systems, as occurs in closed photobioreactors that use sunlight [Mata et al., 2010]

- the optical fiber does not carry electricity

- the optical fiber gives off UV and infrared free light. This allows to give microalgae only the portion of the electromagnetic spectrum necessary for photosynthesis (PAR).

- it is possible to select the electromagnetic spectrum, in order to use a smaller part of the PAR, the one that favors the photosynthetic processes in microalgae, that is the wavelengths that correspond to the red and blue / violet colors [Choi et al., 2015 ].

- it is possible to subject the culture to intermittent light / dark with variable frequencies, in order to characterize the final product of the plant, since, at different light frequencies, the microalgal cells are stressed and induced to change their composition [Choi et al. , 2015].

- independence from weather conditions and day / night and seasonal cycles

- possibility of conferring, at each stage of development of the microalgal culture, the light intensity necessary to maximize the specific growth rate $\mu$, avoiding the phenomenon of photoinhibition [Chisti, 2007].

\subsubsection{Temperature}

Temperature plays an important role for microalgal growth, microalgae can grow in mixtures at $10-35{ }^{\circ} \mathrm{C}$ but the optimal value is $20^{\circ} \mathrm{C}$ (Chinnasamy et al. 2010). By carrying out studies on outdoor installations, temperature and lighting are related to each other and depend on the climatic conditions of the place where the cultivation is located. Temperatures below $16{ }^{\circ} \mathrm{C}$ can inhibit microalgal growth, while for most species temperatures above $35^{\circ} \mathrm{C}$ are 
lethal. Considering microalgal crops in temperate areas, it is important to take into account the cooling of the reactor, achievable for example by spraying water on the external surface, with corresponding additional costs (Morweiser et al. 2010). In the PBRC, the temperature of the culture will be maintained at optimal values between $28-32{ }^{\circ} \mathrm{C}$; to guarantee the temperature value constantly, a system of radiant panels will be installed below the culture macrovolume. Through the thermal conductivity of the fluid, the heat will propagate throughout the microalgal culture. In the separation macrovolume sedimentation must be favored, therefore there will be no heating.

\subsection{3 pH and dissolved oxygen}

$\mathrm{pH}$ values in the mixture in which microalgae are grown can vary from 4 to 12 , but neutrality seems to be the best value for many species of microalgae (Chinnasamy et al. 2010). Even the dissolved oxygen present in the mixture can affect growth, concentration values greater than 4 times the oxygen saturation concentration can create inhibition (Chisti 2007) or limit the photosynthesis rate (Pawlowski et al. 2015). The pH defined for the PBRC system varies between $8-11$

\subsubsection{Nutrients}

The doses of nutrients (carbon dioxide, nitrogen, phosphorus, potassium) necessary for the growth of microalgae must be determined in a stoichiometric way with respect to their composition. For the related calculations, see the next paragraph.

\subsubsection{Mixing}

In large scale plants for the production of microalgae, mixing is essential to continuously expose cells to photons, which would otherwise be in shadow areas, and to avoid algae sedimentation [Amicarelli et al., 2012].Since there are no shaded areas in the PBRC, minimal mixing will be required. This will be ensured through the insufflation of $\mathrm{CO}_{2}$ from below and thanks to the mass transport due to the thermal gradient due to underfloor heating: first the heat passes by conduction from the surface to the adjacent fluid particles, so that the energy thus transmitted increases the internal energy and the temperature of the particles, these particles then move towards a region of the fluid at a lower temperature and mix with it, transferring part of their energy to other particles. Further input to mixing comes from the slow progress (in the regime of "communicating vessels"), balanced and moderate as befits the ongoing processes, as well as from the insufflation of NPK nutrients, such as liquid fertilizers, through injectors diffused along the entire orthogonal section to the existing laminar flow, at each inlet agitated.

\subsubsection{Nutrient modeling}

\section{Calculation of the inoculum speeds inside the pipe}

With reference to the Chlorella inoculation, it is assumed to use a 2" tubing that allows to calculate the inoculum velocity in the PBRC adduction tubing

$v_{\text {inoculo }}=\frac{\mathrm{v}_{\text {sinuoso }} * \mathrm{~A}_{\text {percorso sinuoso }}}{\mathrm{A}_{2}}=\frac{3,33 \frac{\mathrm{m}}{\mathrm{H}} * 0,6 \mathrm{~m}^{2}}{0,001962 \mathrm{~m}^{2}}=1019,36 \frac{\mathrm{m}}{\mathrm{H}} * \frac{1 \mathrm{H}}{3600 \mathrm{~s}}=0,283 \frac{\mathrm{m}}{\mathrm{s}}$ 
Table 3: Inoculation speed

\begin{tabular}{|l|c|c|c|c|c|}
\hline data & u.m. & value & u.m. & value & note \\
\hline Inoculation speed & $\mathrm{v} 2(\mathrm{~m} / \mathrm{h})$ & 1019,36 & $\begin{array}{c}\mathrm{v} 2 \\
(\mathrm{~m} / \mathrm{s})\end{array}$ & 0,283 & \\
\hline $\begin{array}{l}\text { Internal tube diameter for } \\
\text { inoculum inlet }\end{array}$ & $\mathrm{d} 2(\mathrm{~m})$ & 0,053 & 2 "pipe defined \\
\hline $\begin{array}{l}\text { Internal area of 2" tube for } \\
\text { inoculation passage }\end{array}$ & $\mathrm{A} 2 "(\mathrm{~m} 2)$ & 0,001962 & & & \\
\hline
\end{tabular}

\section{Calculation of the inoculum speed leaving the diffusers}

With a $1 \frac{1}{2}$ "diffuser diameter, the inoculum speed at the diffuser outlet will be equal to:

$v_{\text {inoculo }}=\frac{\mathrm{Q}_{0}}{\mathrm{~A}_{\text {diffusore }}}=\frac{2 \frac{\mathrm{m}^{3}}{\mathrm{H}}}{0,000230 \mathrm{~m}^{2}}=8695 \frac{\mathrm{m}}{\mathrm{H}} * \frac{1 \mathrm{~h}}{3600 \mathrm{~s}}=2,41 \frac{\mathrm{m}}{\mathrm{s}}$

The inoculum mass flow rate into the tank is calculated:

$m_{\text {inoculo }}=$ p $_{\text {inoculo }} * Q_{0}=1,34 \frac{\mathrm{Kg}}{\mathrm{m}^{3}} * 2 \frac{\mathrm{m}^{3}}{\mathrm{~h}}=2,68 \frac{\mathrm{Kg}}{\mathrm{h}}$

$Q_{\text {volumetrica }}=v_{\text {inoculo }} * A_{2}=0,283 \frac{\mathrm{m}}{\mathrm{s}} * 0,001962 \mathrm{~m}^{2}=0,000555 \frac{\mathrm{m}^{3}}{\mathrm{~s}}$

Table 4: Inoculum injection diffuser characteristics

\begin{tabular}{|c|c|c|c|c|c|}
\hline data & Unit measure & value & u.m. & value & note \\
\hline $\begin{array}{l}\text { internal diameter } 1 / 2 \\
\text { "injection inoculation } \\
\text { diffusers }\end{array}$ & $\begin{array}{l}\text { D. speakers } \\
(\mathrm{mm})\end{array}$ & 17,120 & $\mathrm{~m}$ & 0,01712 & \\
\hline $1 / 2$ "speaker area & $\begin{array}{l}\text { A. diffuser } \\
\left(\mathrm{m}^{2}\right)\end{array}$ & 0,000230 & & & \\
\hline $\begin{array}{l}\text { inoculation speed in the } 1 / 2 \\
\text { "diffuser }\end{array}$ & $\begin{array}{l}\text { v. diffuser inoculum } \\
(\mathrm{m} / \mathrm{h})\end{array}$ & 8695 & $\mathrm{~m} / \mathrm{s}$ & 2,41 & \\
\hline inlet mass flow rate & $\begin{array}{l}\text { m. inoculum } \\
\mathrm{Kg} / \mathrm{h}\end{array}$ & 2,68 & & & \\
\hline $\begin{array}{l}\text { Inoculum volume flow rate } \\
\text { at the inlet }\end{array}$ & $\begin{array}{l}\text { Volumetric Q } \\
\mathrm{m}^{3} / \mathrm{s}\end{array}$ & 0,000555 & $1 / \mathrm{s}$ & 0,555 & $\mathrm{Q}=\mathrm{V}^{*} \mathrm{~A}$ \\
\hline
\end{tabular}




\section{Calculation of the mass flow of $\mathrm{CO}_{2}$}

The dose of carbon dioxide necessary for the growth of microalgae is determined as follows:

$m_{c o_{2}}=w_{c} * f_{m} * \frac{P M_{C O_{2}}}{P M_{C}}=0,012 \frac{k g}{s} * 0,521 * \frac{44}{12}=0,023 \frac{k g_{c o_{2}}}{\mathrm{~s}} * 3600 \frac{\mathrm{s}}{\mathrm{h}}=82,80 \frac{\mathrm{kg}_{\mathrm{co}_{2}}}{\mathrm{~h}}$

Table 5: Flow rate values $\mathrm{CO} 2$

\begin{tabular}{|c|c|c|}
\hline massive carbon fraction in microalgae & $f_{m}=($ adim $)$ & 0,521 \\
\hline CO2 molecular weight & $\mathrm{g} / \mathrm{moli}$ & 44 \\
\hline Molecular weight C & $\mathrm{g} / \mathrm{moli}$ & 12 \\
\hline annual biomass production & $w_{c}=\mathrm{kg} / \mathrm{s}$ & 0,012 \\
\hline
\end{tabular}

\begin{tabular}{|l|c|c|}
\hline massive carbon fraction in microalgae & $\mathrm{mco} 2=\mathrm{kgco} 2 / \mathrm{s}$ & 0,023 \\
\hline $\mathrm{CO} 2$ molecular weight & $\mathrm{mco} 2=\mathrm{kgco} 2 / \mathrm{h}$ & 82,80 \\
\hline
\end{tabular}

Table 6: $\mathrm{CO}_{2}$ density value (from the engineer manual)

\begin{tabular}{|c|c|c|}
\hline Density $\mathrm{CO}_{2}$ & $\mathrm{p}=(\mathrm{Kg} / \mathrm{m} 3)$ & 1,840 \\
\hline
\end{tabular}

For each ton of biomass produced it takes about $1,83 \mathrm{t}$ of $\mathrm{CO}_{2}($ Chisti, 2007)

\section{Calculation of the volumetric flow rate of $\mathrm{CO} 2$}

The calculation of the volume flow is thus defined:

$Q_{\mathrm{Co}_{2}}=\frac{\mathrm{m}_{\mathrm{CO}_{2}}}{\rho_{\mathrm{CO}_{2}}}=\frac{0,023 \frac{\mathrm{kg}}{\mathrm{s}}}{1,84 \frac{\mathrm{kg}}{\mathrm{m}^{3}}}=0,0125 \frac{\mathrm{m}^{3}}{\mathrm{~s}}$

Table 7: $\mathrm{CO}_{2}$ Volume flow value

\begin{tabular}{|c|c|c|}
\hline Volume flow CO2 & QCO2 $=\mathrm{m} 3 / \mathrm{s}$ & 0,0125 \\
\hline
\end{tabular}

\section{Injection piping analysis $\mathrm{CO}_{2}$}

\section{Data:}

Table 8: Dimensional characteristics of the injection tube $\mathrm{CO} 2$

\begin{tabular}{|l|c|c|}
\hline Inner tube diameter 1 " & dco2(mm) & 0,028 \\
\hline Pipe area 1 " & A co2 (m2) & 0,000609 \\
\hline
\end{tabular}




\section{Calculation of the $\mathrm{CO}_{2}$ speed}

Using the following formula, the $\mathrm{CO}_{2}$ rate is determined

Table 9: $\mathrm{CO}_{2}$ speed value

\begin{tabular}{|c|c|c|c|c|}
\hline data & u.m. & result & u.m. & result \\
\hline $\mathrm{CO}_{2}$ speed & $\mathrm{vco} 2(\mathrm{~m} / \mathrm{h})$ & 20,52 & $\mathrm{~m} / \mathrm{s}$ & 0,00563 \\
\hline
\end{tabular}

\section{Nutrient analysis: Nitrogen, Phosphorus, Potassium}

Table 10 summarizes the quantities of the main nutrients that must be supplied to the Chlorella microalgae.

Table 10: N,P,K values

\begin{tabular}{|c|c|c|c|}
\hline data & u.m. & result & u.m. \\
\hline N nitrogen flow & $\mathrm{Kg} / \mathrm{h}$ & 2,237 & $30 \% *$ mass flow to be integrated \\
\hline P phosphorus flow & $\mathrm{Kg} / \mathrm{h}$ & 1,491 & $20 \% *$ mass flow to be integrated \\
\hline K potassium flow & $\mathrm{Kg} / \mathrm{h}$ & 0,746 & $10 \% *$ mass flow to be integrated \\
\hline
\end{tabular}

\section{Calculation of the amount of water to be supplied to the system}

The mass flow rate of water to be supplied to the system is calculated as follows:

$$
\begin{aligned}
& m_{\mathrm{H}_{2} \mathrm{O}}=0,5 * w_{\mathrm{H}^{i n}}^{\text {in }} * m_{\text {giornaliera biom }} * \frac{P M_{\mathrm{H}_{2} \mathrm{O}}}{P M_{\mathrm{H}}}=0,5 * 0,080 * \frac{18}{1} \frac{\mathrm{g} / \mathrm{moli}}{\mathrm{g} / \mathrm{moli}} * 1029 \frac{\mathrm{kg}_{\mathrm{H} 2 \mathrm{O}}}{\mathrm{d}}=740,88 \frac{\mathrm{kg}_{\mathrm{H} 2 \mathrm{O}}}{\mathrm{d}} \\
& m_{\mathrm{H}_{2} \mathrm{O}}=\frac{740,88 \frac{\mathrm{kg} \mathrm{H}_{2 \mathrm{O}}}{\mathrm{d}}}{24 \frac{\mathrm{h}}{\mathrm{d}}}=30,87 \frac{\mathrm{kg}_{\mathrm{H} 2 \mathrm{O}}}{\mathrm{h}}
\end{aligned}
$$

\begin{tabular}{|c|c|c|c|c|c|}
\hline data & u.m. & values & & & note \\
\hline $\mathrm{PM} \mathrm{H} 2 \mathrm{O}$ & $\mathrm{g} / \mathrm{moli}$ & 18 & & & \\
\hline PM hydrogen & $\mathrm{g} / \mathrm{moli}$ & 1 & & & \\
\hline $\begin{array}{l}\text { mass flow rate of water } \\
\text { to be supplied to the } \\
\text { system }\end{array}$ & $\begin{array}{c}\mathrm{mH}_{2} \mathrm{O}=(\mathrm{Kg} / \mathrm{d} \\
\text { ay) }\end{array}$ & 740,88 & $\mathrm{~kg} / \mathrm{h}$ & 30,87 & $\begin{array}{c}m_{\mathrm{H}_{2} \mathrm{O}}=0,5 * w^{i n} * m_{\text {giornaliera biom }} \\
* \frac{P M_{\mathrm{H}_{2} \mathrm{O}}}{P M_{\mathrm{H}}}\end{array}$ \\
\hline $\begin{array}{l}\text { Massive fraction of } \\
\text { hydrogen }\end{array}$ & whiN (adim) & 0,080 & & & \\
\hline
\end{tabular}

Table 11: $\mathrm{H}_{2} \mathrm{O}$ values to be supplied to the system 


\subsection{Collection Systems}

\subsubsection{Ultrasound cell breaking}

The cell destruction mechanism results from intensive cutting induced by sonication of the suspension at sound frequencies above $20 \mathrm{kHz}$. A magnetostrictive or piezoelectric transducer converts the alternating current of a electric oscillator in mechanical waves that are transmitted to the suspension through a metal probe (usually titanium) vibrating with the same frequency as the oscillator. Sound waves create many micro bubbles in various suspended nucleation sites, which implode during the period of rarefaction of sound waves. This cavitation phenomenon (formation, growth, and collapse of vapor-filled bubbles) produces intense local shock waves, and intense local shear gradients are generated that cause cells to deform beyond the elasticity and rupture limits [Richmond, 2004]. Ultrasound is usually used as a method of cell destruction for the extraction of proteins from microalgae, since temperature and stresses modify the structure of these compounds [Bermejo et al., 2001]. Mechanical cell disintegration is generally preferred as it avoids further chemical contamination of algal preparation while preserving most of the material's functionality within the cell [Chisti \& Moo-Young, 1986].
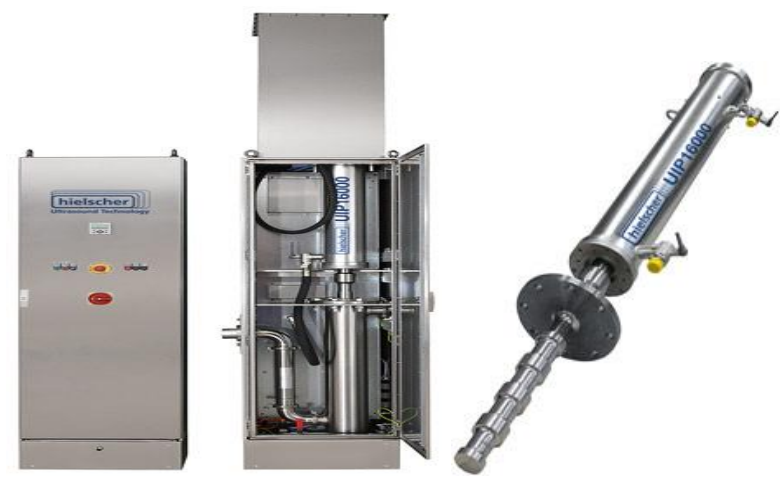

Fig.10 Example of a powerful ultrasound processor

\subsubsection{Sedimentation and suspension of microalgae}

Following the breakdown of the microalgae, the flow is introduced, into the collection macrovolume, horizontally through a perforated tube placed at a level equal to half that of the free surface, as shown in fig. 11. The already destroyed microalgal cells will proceed very slowly towards the opposite wall. During this process, the particles with a higher specific gravity will sediment downwards due to the effect of gravity. On the contrary, the lighter cells will tend to rise towards the free surface.

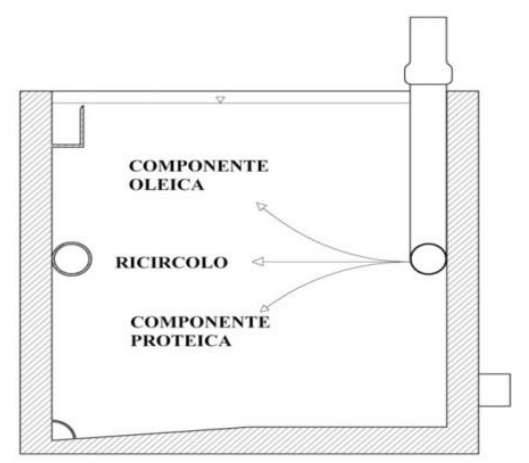

Fig.11 Sectional view of the collection volume 
Success in removing solids by gravity settling depends heavily on the density of the microalgae particles. Edzwald (1993) found that low density microalgae particles do not settle well and are not successfully separated. To favor this process, flocculation, already often used to increase the efficiency of sedimentation by gravity, can be used. It is a process in which the dispersed particles are aggregated together to form larger particles for sedimentation. [Chen et al., 2011]. There are various types of flocculation: self-flocculation, chemical coagulation, with inorganic coagulants, with organic flocculants, combined flocculation and with electrolytic process. Instead, to favor the suspension of lighter cells (oleic component of microalgae), flotation can be used. Flotation is a gravity separation process in which air or gas bubbles they stick to solid particles and then bring them to the liquid surface. Chen et al. (1998) noted that flotation is more beneficial and effective than sedimentation with regard to the removal of microalgae. Flotation can capture particles with a diameter of less than $500 \mu \mathrm{m}$ through the collision between a bubble and a particle and the subsequent adhesion of the bubble and the particle [Yoon \& Luttrell, 1989]. Based on the size of the bubbles used in the flotation process, the applications can be divided into dissolved air flotation (DAF), dispersed air flotation and electrolytic flotation.

Studies are underway for a separation of the microalgal biomass by electroplating with spiral electrodes in iron and aluminum. Electroflotation can be considered an effective technique for the separation of microalgal biomass, but additional work is needed to explore ways to avoid increasing levels of toxic metals in the discarded effluent [Baierle et al., 2015].

A significant alternative derives from the joint use of electro-floatation and pushed gravimetric separation, by means of the system GSMF inserted between input and outputs (two distinct blocks of honeycomb). GSMF (gravimetric separator mixtures fluid, liquid and gas) is an Italian patent [Lavanga and Farné, 2014]

\subsubsection{Calculation of oleic, protein content, recirculation}

It has been assumed to distribute the biomass with the following percentages

$\%$ protein content $=64 \%$

$\%$ oleic content $=34 \%$

$\%$ recirculation content $=2 \%$

Using the formula below, it was possible to determine the masses of the protein, oleic and recirculating contents Mass protein content $=\%$ protein content $*$ Hourly biomass production

Protein content mass $=\%$ oleic content $*$ Hourly biomass production

Mass content to be recirculated $=\%$ content recirculated $*$ Hourly production of biomass

Table 12: Nutrients to be supplied to the system

\begin{tabular}{|l|c|c|}
\hline data & u.m. & values \\
\hline$\%$ protein content & $\%$ & 0,640 \\
\hline
\end{tabular}


Asian Journal of Applied Science and Technology

Volume 4, Issue 3, Pages 145-166, July-September 2020

\begin{tabular}{|l|c|c|}
\hline$\%$ oleic content & $\%$ & 0,340 \\
\hline$\%$ recirculation content & $\%$ & 0,020 \\
\hline mass protein content & $m_{\text {proteico }}==\mathrm{Kg} / \mathrm{h}$ & 27,443 \\
\hline mass oleic content & $m_{\text {oleico }}=\mathrm{Kg} / \mathrm{h}$ & 14,579 \\
\hline recirculation content mass & $m_{\text {ricircolo }}=\mathrm{Kg} / \mathrm{h}$ & 0,858 \\
\hline
\end{tabular}

\subsection{Calculation of flow rates}

\subsubsection{Extracted from the system}

The extracted flow rate consists of the sum of the mass of the protein and oleic content

$m_{\text {estratta }}=m_{\text {oleico }}+m_{\text {proteico }}=27,443+14,579=42,022 \frac{\mathrm{Kg}}{\mathrm{h}}$

Table 13: Flow rate extracted from the system

\begin{tabular}{|c|c|c|}
\hline data & u.m. & values \\
\hline$m_{\text {estratta }}$ & $\mathrm{Kg} / \mathrm{h}$ & 42,022 \\
\hline
\end{tabular}

\subsubsection{To be integrated into the system}

The flow rate to be integrated into the system is calculated:

$$
\begin{gathered}
m_{\text {integrare }}=m_{\text {estratta }}-\left(m_{\text {ricircolo }}+m_{H 2 O}+m_{\text {inoculo }}\right)=42,022 \frac{\mathrm{Kg}}{\mathrm{h}}-(0,858+30,87+2,68) \\
=7,457 \frac{\mathrm{Kg}}{\mathrm{h}}
\end{gathered}
$$

Table 14: Mass flow rate to be integrated into the system

\begin{tabular}{|c|c|c|}
\hline data & u.m. & result \\
\hline$m_{\text {integrare }}$ & $\mathrm{Kg} / \mathrm{h}$ & 7,457 \\
\hline
\end{tabular}

The flow rate to be integrated takes place in percentage by means of the nutrients $\mathrm{N}, \mathrm{P}, \mathrm{K}$ in the following quantities:

$$
\begin{aligned}
& m_{N \text { da integrare }}=30 \% * m_{\text {integrare }}=2,237 \frac{\mathrm{kg}}{\mathrm{h}} \\
& m_{P \text { da integrare }}=20 \% * m_{\text {integrare }}=1,491 \frac{\mathrm{kg}}{\mathrm{h}} \\
& m_{K \text { da integrare }}=10 \% * m_{\text {integrare }}=0,746 \frac{\mathrm{kg}}{\mathrm{h}}
\end{aligned}
$$


Table 15: Nutrients to be integrated into the system

\begin{tabular}{|l|l|c|c|}
\hline u.m. data & u.m. data & result & u.m. \\
\hline Nitrogen mass flow rate N & $\begin{array}{l}\text { Nitrogen mass flow } \\
\text { rate N }\end{array}$ & 2,237 & $30 \% *$ mass flow to be integrated \\
\hline Phosphorus mass flow rate P & $\begin{array}{l}\text { Phosphorus mass } \\
\text { flow rate P }\end{array}$ & 1,491 & $20 \% *$ mass flow to be integrated \\
\hline Potassium mass flow rate K & $\begin{array}{l}\text { Potassium mass flow } \\
\text { rate K }\end{array}$ & 0,746 & $10 \% *$ mass flow to be integrated \\
\hline
\end{tabular}

\subsubsection{Collection of separate parts of microalgae}

Following the separation through the collection volume, the three micro-algae products will be taken on the wall opposite the entrance:

- the protein component with a perforated tube, located on the bottom of the tank; the floor is inclined to allow a more effective collection.

- the oleic component with a cantilevered step positioned at a millimeter level under the free surface (Fig. 12)

- inoculation with perforated tube placed at an intermediate level.

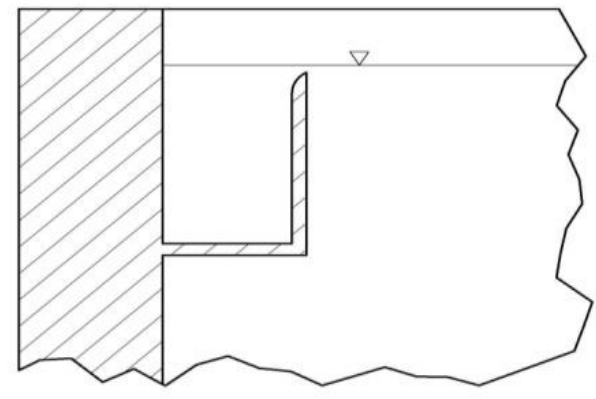

Fig.12 Detail of the step for collecting the oleic component

\section{Conclusions}

The PBRC (Photo Bio Reactor Continuous) presented, is aimed at the production of oleic and protein substances to be used as raw material in the energy sector (production of biofuels), pharmaceutical, agri-food, cosmetic. This device overcomes many of the limitations of the existing systems, and reaches high rates of productivity. PBRC offers a significant contribution to the production of energy from renewable sources and to the problem of limiting $\mathrm{CO}_{2}$ emissions into the atmosphere, which is used as a nutrient for the growth of microalgae. As it is clear from the foregoing description, in the described device, it is possible to obtain large amounts of oleic and of protein material from small amounts of algae. For a full ecological application of the device, the energy sources, to be used to favour the growth of the algae and their treatment, will be of renewable type. 


\section{Acknowledgments}

Dr. Vito Lavanga, freelance researcher and inventor.

\section{Bibliography}

- Lavanga V., Farné S., PBRC https://patentscope.wipo.int/search/en/detail.jsf?docId=WO2016092583 (algae to food/feed/biofuel, in urban and periurban).

- Lavanga V., Farné S., SDNA https://patentscope.wipo.int/search/en/detail.jsf?docId=WO2016092576 (lights diffusor homogenous by side emission fiber).

- Lavanga V., Farné S., CMTC https://patentscope.wipo.int/search/en/detail.jsf?docId=WO2016092580 (capture radiative spectrum and thermal energy).

- Lavanga V., Farné S., GSMF https://patentscope.wipo.int/search/en/detail.jsf?docId=WO2016092577 (gravimetric separator mixtures fluid, liquid and gas).

- Mata Teresa M., Martins Antonio A., Caetano Nidia. S.; (2010); Microalgae for biodiesel production and other applications: A review; Renewable and Sustainable Energy Reviews.

- Molina Grima E., Acién Fernández F.G., García Camacho F., Chisti Yusuf; (1999); Photobioreactors: light regime, mass transfer, and scaleup; Journal of Biotechnology.

- Molina Grima E., García Camacho F., Sánchez Pérez J.A., Fernández Sevilla J., Acién Fernández F.G., Contreras Gómez A.; (1994); A mathematical model of microalgal growth in light limited chemostat cultures; J. Chem. Technol. Biotechnol.

- Brennan L., Owende P. (2010) Biofuels from microalgae - A review of technologies for production, processing, and extractions of biofuels and co-products. Renewable and Sustainable Energy Reviews.

- Amicarelli Vera, Paiano Annarita, Lobefaro Leonarda; (2012); Le microalghe nel settore dei biocombustibili. Sviluppo e sostenibilità; Energia, ambiente e innovazione.

- Sandnes J.M., Källqvist T., Wenner D., Gislerød H.R.; (2005); Combined influence of light and temperature on growth rates of Nannochloropsis oceanica: linking cellular responses to large-scale biomass production; J Appl Phycol.

- Richmond A.; (2004); Handbook of microalgal culture: biotechnology and applied phycology; Blackwell Science Ltd., Norma ISPELS VSR 95 Ed.99.

- Choi Yong-Keun, Kumaran Rangarajulu Senthil, Jeon Hyeon Jin, Song Hak-Jin, Yang Yung-Hun, Lee Sang Hyun, Song Kyung-Guen, Kim Kwang Jin, Singh Vijay, Kim Hyung Joo; (2015); LED light stress induced biomass and fatty acid production in microalgal biosystem, Acutodesmus obliquus; Spectrochimica Acta Part A: Molecular and Biomolecular Spectroscopy.

- Chisti Y. (2007); Biodiesel from microalgae, Biotechnology Advances.

- Chinnasamy, S. et al., 2010. Microalgae cultivation in a wastewater dominated by carpet mill effluents for biofuel applications. Bioresource Technology.

- Morweiser, M. et al., 2010. Developments and perspectives of photobioreactors for biofuel production. 
Bermejo, R., Talavera, E.M. \& Alvarez-Pez J.M.; (2001); Chromatographic purification and characterization of $\beta$-phycoerythrin from Porphyridium cruentum. Semipreparative HPLC separation and characterization of its subunits.; J. Chromatogr.

- Chisti, Y., Moo-Young, M., (1986); Disruption of microbial cells for intracellular products. Enzyme Microbiol.

- Edzwald, J.K., (1993); Algae, bubbles, coagulants, and dissolved air flotation. Water Sci. Technol.

- Citrini D., Noseda G.; (1987); Idraulica, seconda edizione, Casa Editrice Ambrosiana.

- Yoon, R.H., Luttrell, G.H.; (1989); The effect of bubble size on fine particle flotation. Miner. Process. Extract. Metal. Rev.: An Int. J. 5.

- Baierle Felipe, John Danielle K., Souza Maiara P., Bjerk Thiago R., Moraes Maria S.A., Hoeltz Michele, Rohlfes Ana L.B., Camargo Maria Emilia, Corbellini Valeriano A., Schneider Rosana C.S.; (2015); Biomass from microalgae separation by electroflotation with iron and aluminum spiral electrodes; Chemical Engineering Journal. 